\title{
Measurements of Turbulent Fluxes of Momentum and Sensible Heat over the Labrador Sea
}

\author{
KARl Bumke, U. KARger, AND K. Uhlig \\ Institut für Meereskunde, Universität Kiel, Kiel, Germany
}

(Manuscript received 18 January 2000, in final form 30 March 2001)

\section{ABSTRACT}

\begin{abstract}
Turbulent fluxes of momentum and sensible heat were estimated from sonic anemometer measurements gathered over the Labrador Sea during a winter cruise of the R/V Knorr. The inertial dissipation method was used to calculate turbulent fluxes of momentum. The resulting drag coefficients agree well with earlier findings. Sensible heat fluxes were computed using both cross-correlation and inertial dissipation techniques. There is good agreement between results from both methods, although there is more scatter in the correlation fluxes than the dissipation fluxes. The inertial dissipation method gives reasonable results even under conditions of high wind speeds and low air temperatures, which combined with the relatively warm sea surface temperatures lead to sensible heat fluxes of several hundred watts per square meter. Sensible heat fluxes obtained from the sonic anemometer measurements agree well with bulk turbulent fluxes according to the formulation of Isemer and Hasse.
\end{abstract}

\section{Introduction}

Deep convection in the ocean is observed only at a few places worldwide. It drives the thermohaline circulation, which accounts for about $50 \%$ of the poleward transport of heat in atmosphere and ocean, and depicts the importance of deep convection for the climate system.

The development of deep convection is forced by airsea interaction, by losses of heat and water vapor by the surface waters, which leads to a destabilization and consecutively to convection in the ocean. To improve our understanding of the processes leading to and resulting from deep convection the Labrador Sea Experiment (Lab Sea Group 1998) took place. Part of that experiment was the cruise of the R/V Knorr in February/ March 1997. A series of oceanographical and meteorological measurements was carried out to investigate air-sea interaction and its role in the development of deep convection.

The objective of the present paper is the analysis of turbulence measurements to obtain the turbulent fluxes of momentum and sensible heat. These estimated fluxes can be used to validate the results of numerical models (Renfrew et al. 2002) or to check whether existing bulk parameterizations (e.g., Bunker 1976; Smith 1980; Large and Pond 1981, 1982; Anderson and Smith 1981;

Corresponding author address: Karl Bumke, Institut für Meereskunde, Universität Kiel, FB 1, Maritime Meteorologie, Düsternbrooker Weg 20, 24105 Kiel, Germany.

E-mail: kbumke@ifm.uni-kiel.de
Isemer and Hasse 1987; Smith 1988; Smith et al. 1992; Anderson 1993; DeCosmo et al. 1996) are valid for conditions as observed over the Labrador Sea during wintertime. Therefore, the main goal of the present paper is to analyze measurements of the turbulent fluxes of momentum and sensible heat and to check the validity of existing parameterizations under such conditions.

\section{The Labrador Sea Experiment}

The primary cruise of the Labrador Sea Experiment took place in February and March 1997 (Fig. 1) on board the R/V Knorr. A mast designed and built especially for purposes of measurements of air-sea interaction was mounted on the foredeck of the R/V Knorr close to the bow (Fig. 2). Turbulence measurements by the Institut für Meereskunde Kiel included a sonic anemometer, mounted on a crossbar at the top of this mast, corresponding to a height of about $18.5 \mathrm{~m}$ above the sea surface. This sonic anemometer (manufactured by METEK, Hamburg, Germany) sampled at $30 \mathrm{~Hz}$. The raw data of the three wind components and the temperature were stored. At a lower rate of $5 \mathrm{~Hz}$ the roll and pitch angles, measured by a system consisting of oil damped pendulars, were recorded to quantify the ship's motions due to wind waves and swell. This information was used for a coordinate transformation of the measured longitudinal and lateral wind components.

Mean meteorological sensors were those of the ship's Improved Meteorological Instrumentation (IMET) measurements system, for example, a pressure sensor, a hy- 


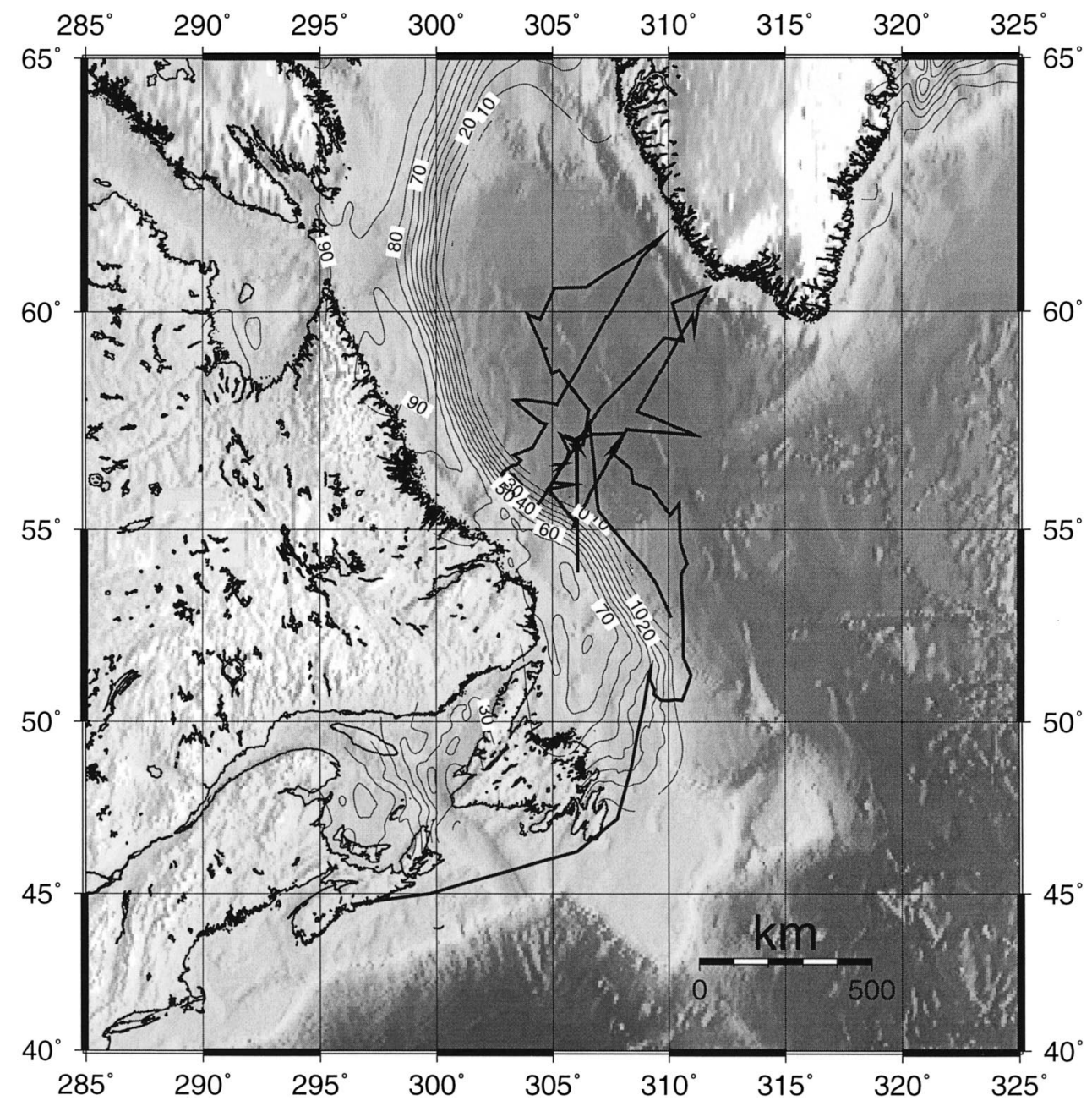

FIG. 1. Labrador Sea Experiment: Cruise of the R/V Knorr in Feb/Mar 1997. The thin solid lines give the ice concentration (\%) as estimated from satellite data (H. Berndt 1999, personal communication).

grometer, intake temperature, a thermistor, and a cup anemometer. These measurements were taken on the ship's foremast at a height of about $19.5 \mathrm{~m}$. The ship's velocity and direction were provided by a gyrocompass and a Doppler log with ship's position given via GPS.

\section{Theory}

The turbulent fluxes of momentum were computed using the so-called inertial dissipation method. It is based on the budget of the turbulent kinetic energy $e$, which is given here in its nondimensional form (Large and Pond 1982):

$$
\begin{aligned}
0= & \Phi_{m}\left(\frac{z}{L}\right)-\frac{z}{L}-\frac{\kappa z}{u_{*}^{3}} \frac{\partial\langle w e\rangle}{\partial z}-\frac{\kappa z}{u_{*}^{3}} \frac{\partial}{\partial z} \cdot \frac{\langle w p\rangle}{\rho} \\
& -\frac{\kappa z}{u_{*}^{3}} \varepsilon,
\end{aligned}
$$

where $\Phi_{m}$ is a universal stratification function, $z$ is the height of measurements, $L$ is the Monin-Obukhov length, $\kappa$ is the von Kármán constant, $w$ the vertical wind component, $p$ the pressure, $\rho$ the air density, $u_{*}$ the friction velocity, and $\varepsilon$ the dissipation rate. Equation (1) can be solved for $u_{*}$.

With

$$
S(k)=\alpha \varepsilon^{2 / 3} k^{-5 / 3}
$$

and Taylor's principle of the frozen turbulence

$$
k S(k)=f S(f)
$$

where $\alpha$ is the Kolmogoroff constant, $k$ the wavenumber, $f$ the frequency, and $S$ the spectral energy density, we get the friction velocity

$$
u_{*}=\left(\frac{2 \pi \kappa z}{\langle u\rangle}\right)^{2 / 3} \frac{S_{u, w}(f) f^{5 / 3}}{\alpha_{u, w}(2 \pi)^{2 / 3}}\left[\Phi_{m}\left(\frac{z}{L}\right)-\left(\frac{z}{L}\right)\right],
$$

neglecting the transport term (term 3 of the right-hand side) and the pressure term (term 4 of the right-hand side) according to earlier studies (e.g., Large and Pond 


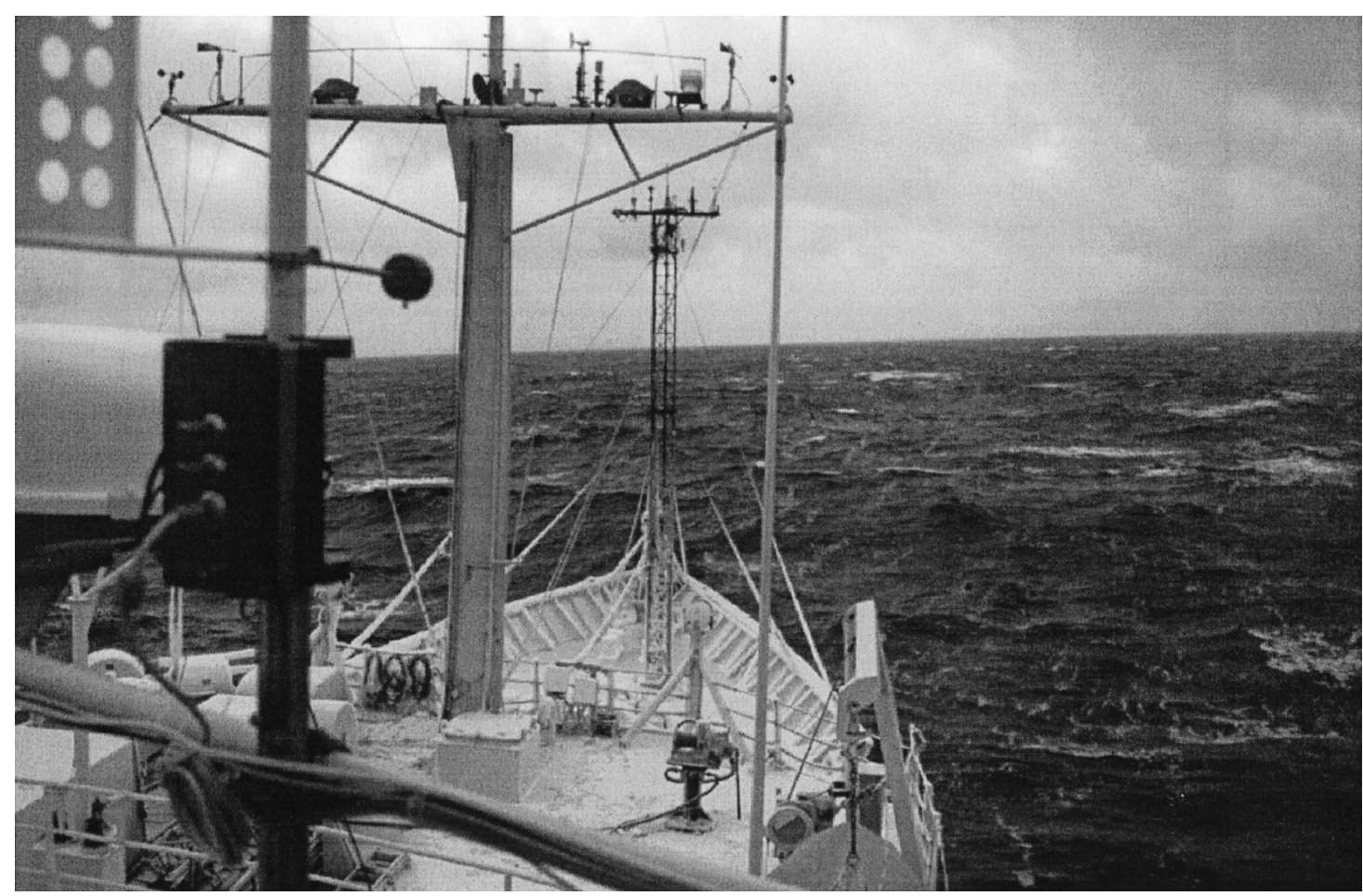

FIG. 2. Photo of the foreship of R/V Knorr taken from the observation deck. Instruments for turbulence measurements are mounted on the t-bar of the bowmast at a height of approximately $18.5 \mathrm{~m}$ above sea level. The foremast, which is approximately $11 \mathrm{~m}$ behind the bow mast, carries temperature and wind speed sensors of the ship's IMET.

1981). Here $\langle u\rangle$ is the mean wind speed. Recent studies have shown the importance of both terms for situations with unstable stratification (e.g., Yelland and Taylor 1996). Therefore, an imbalance term has been introduced (e.g., Yelland and Taylor 1996; Dupuis et al. 1997) for situations with nonneutral stability, which is defined as

$$
\Phi_{\mathrm{imb}}=\frac{\kappa z}{u_{*}^{3}} \cdot \frac{\partial\langle w e\rangle}{\partial z}+\frac{\kappa z}{u_{*}^{3}} \frac{\partial}{\partial z}\left(\frac{\langle w p\rangle}{\rho}\right)
$$

When estimating the friction velocity from the budget of the turbulent kinetic energy another problem occurs, because the Monin-Obukhov length also depends on $u_{*}$. To solve this problem there are two possibilities: using a bulk parameterization to compute the friction velocity and buoyancy flux and hence obtain the MoninObukhov length (e.g., Large and Pond 1982) or to derive $u_{*}$ iteratively by making use of the fluxes from the sonic anemometer measurements. Thus, the friction velocity was derived by reinjecting $u_{*}$ in the calculation of the Monin-Obukhov length until convergence for $u_{*}$ was reached. The latter was suggested by Dupuis et al. (1997). In the following it is called the dissipationdissipation (DD) algorithm, while the bulk method is called the dissipation-bulk (DB) algorithm.

The inertial dissipation method for buoyancy fluxes is based on the budget of scalar variance (Large and
Pond 1982), which under horizontal homogeneous and stationary conditions simplifies to

$$
\langle w T\rangle \frac{\partial T}{\partial z}+\frac{1}{2} \frac{\partial\left\langle w T^{2}\right\rangle}{\partial z}+N_{T}=0 .
$$

Neglecting the transport term and applying Eq. (6) to the virtual temperature $T_{v}$ instead of the air temperature $T$ it simplifies to

$$
\left\langle w T_{v}\right\rangle=\left[\frac{\kappa z u_{*} N_{T_{v}}}{\Phi_{T_{v}}(z / L)}\right]^{1 / 2},
$$

where $N_{T}$ and $N_{T_{v}}$ are the turbulent dissipation rates for the temperature and virtual temperature variance, and $\Phi_{T_{v}}$ is a universal stratification function. Here $N_{T}$ or $N_{T_{v}}$ can be inferred from spectral energy densities in the inertial subrange according to

$$
S_{T}(f)=\beta_{T}^{\prime} \varepsilon^{-1 / 3} N_{T}\left(\frac{2 \pi}{\langle u\rangle}\right)^{-2 / 3} f^{-5 / 3},
$$

where $\beta_{\mathrm{T}}^{\prime}$ is 0.8 (Large and Pond 1982). The von Kármán constant is set to 0.4 , and the Kolmogoroff constant $\alpha$ is set to 0.52 (Högström 1996). The universal stratification functions are adopted from Businger et al. (1971) and Dyer (1974).

Synoptic conditions were characterized by relatively high sea surface temperatures (about $0^{\circ}-3^{\circ} \mathrm{C}$ ) compared to the low air temperatures (about $-15^{\circ}-0^{\circ} \mathrm{C}$ ). Therefore, 
free convection has to be taken into account, which is done according to Gravech et al. (1998). For that purpose the integrated Businger and Dyer or Kansas-type relationship for unstable conditions was replaced by

$$
\Psi_{u}=\frac{\Psi_{\text {Kansas }}+\left(\frac{z}{L}\right)^{2} \Psi_{\text {convective }}}{1+\left(\frac{z}{L}\right)^{2}},
$$

where

$$
\begin{aligned}
\Psi_{\text {convective }}= & \frac{3}{2} \frac{\ln \left(y^{2}+y+1\right)}{3} \\
& -\sqrt{3} \arctan \left(\frac{2 y+1}{\sqrt{3}}\right)+\frac{\pi}{\sqrt{3}} .
\end{aligned}
$$

Here $y=[1-12.87(z / L)]^{1 / 3}$ is the stratification function for conditions of free convection. Further, the vectoraveraged wind speed was replaced by the scalar-averaged wind speed.

To derive turbulent fluxes making use of the inertial dissipation method a number of conditions have to be fulfilled. First, the dissipation rate must be estimated from spectral energy densities at frequencies in the inertial subrange. The inertial subrange is characterized by spectral energy densities, which are proportional to $f^{-5 / 3}$. Second, conditions should be locally isotropic, which is reflected in a ratio of the spectral energy density of the lateral to the longitudinal component of 4:3. All measured spectra were checked for both conditions at frequencies ranging from 3 to $12 \mathrm{~Hz}$ to estimate individually for each time series the low and high frequency end of a $3-\mathrm{Hz}$ broad frequency interval, which has the smallest deviations to the $-5 / 3$ law and the $4: 3$ ratio. Time series with deviations of more than $10 \%$ from the $-5 / 3$ law or ratios of the spectral energy densities of the vertical to the longitudinal wind component less than 1 were ejected. The remaining deviations from local isotropy were corrected following Wucknitz (1978):

The influence of the flow distortion on the measurements by the ship itself, resulting in inaccuracies of wind measurements, was minimized by applying the results of a flow distortion study. This study was performed by the Southampton Oceanography Centre (Moat and Yelland 1998). In summary, the main results of this study were that the vertical displacement of the flow at the sonic site was $0.78 \mathrm{~m}$ and the percentage error in wind speed only $-0.67 \%$. The vertical displacement of wind speed measurements of the ship's IMET was $1.37 \mathrm{~m}$ with a percentage error in wind speed of $0.99 \%$. It should be mentioned that the flow distortion study did not investigate the disturbances resulting from the ship's superstructure, which may also influence turbulence measurements.

Finally, the spectra were checked for spikes. To avoid flow distortion from instruments mounted on the same

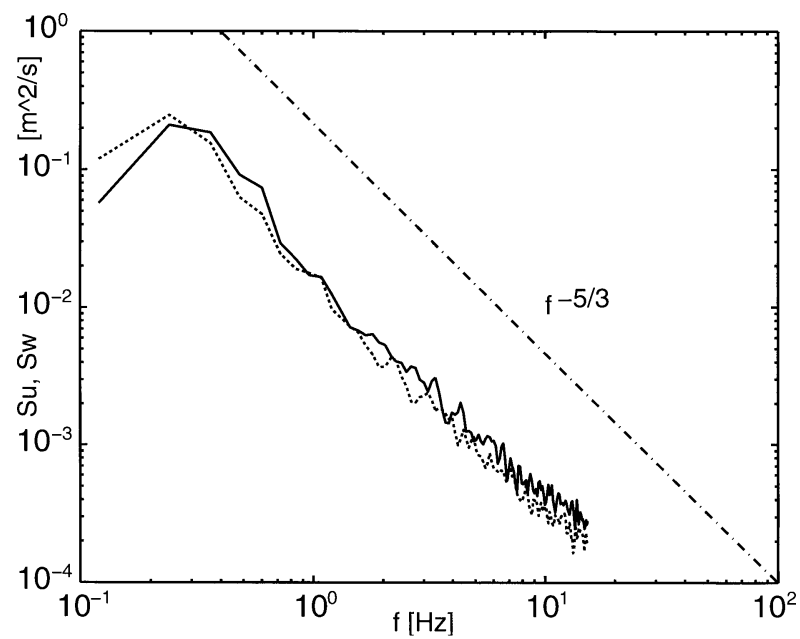

FIG. 3. Spectra of the longitudinal (dotted line) and vertical component of the wind (solid line) for conditions with swell, as indicated by Fig. 4. The dashed-dotted line indicates the $f^{-5 / 3}$ slope.

crossbar, only data where the relative wind direction was within a range of $\pm 40^{\circ}$ of the bow, were used.

Sensible heat fluxes were also estimated using the cross-correlation method. The cross-correlation technique is based on measurements of the exchanges in the atmospheric surface layer, where the fluctuating vertical velocity transports air properties up and down. The sensible heat flux $H$ is defined by

$$
H=\rho c_{p}\langle w T\rangle,
$$

where $c_{p}$ is the specific heat at constant pressure. Following Reynolds averaging convention, the vertical velocity $w$ and air temperature $T$ are separated into a mean (angle brackets) and fluctuation (primes), and are given by $\langle w\rangle+w^{\prime}$ and $\langle T\rangle+T^{\prime}$.

Integration of the $w, T$ cospectrum over all contributing frequencies gives the covariance or sensible heat flux. Unfortunately, the method is highly sensitive to instrument orientation, which hampers the ability of this method on moving platforms such as ships. An analysis of pitch and roll angles showed that the variation of the pitch angles is on average a factor of 3 smaller than the variation of the roll angles. Therefore, the ship's motions were estimated approximately only from measurements of the roll angles directly at the sonic anemometer, which were used to compute the local orbital velocity at the instruments location. That simple approach includes the assumption that there is a lack of correlation between the heave and the temperature. Figure 3 shows resulting spectra of the corrected $u$ and $w$ components of the wind for a situation with swell (Fig. 4) at a wind speed of approximately $12 \mathrm{~m} \mathrm{~s}^{-1}$. Since the motions of the ship were not fully corrected, the computed fluxes of sensible heat based on the cross-correlation method are expected to show additional scatter.

Finally, both cross-correlation and dissipation techniques need a correction because temperatures taken 


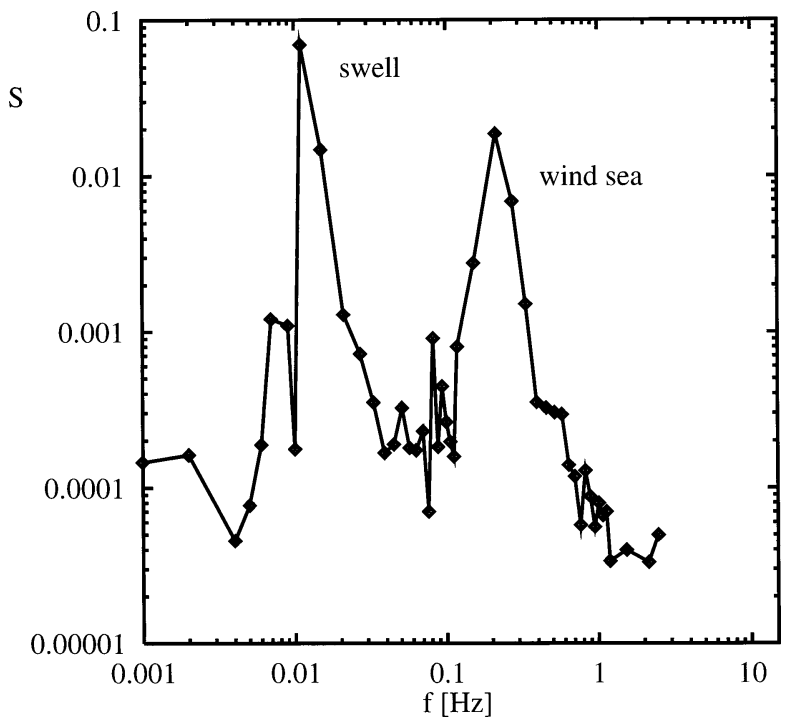

FIG. 4. Raw spectra of the ship's vertical displacement for conditions with swell. The raw data of these measurements were kindly provided by Fred Dobson, Bedford Institute of Oceanography, Canada.

from the sonic anemometer are close to the virtual temperature (Kaimal and Gaynor 1991). This correction was adopted from Dupuis et al. (1997).

\section{Results}

\section{a. Imbalance term}

The imbalance term was deduced from the assumption that at the same wind speed, neutral drag coefficients should not depend on stability. Thus, the whole dataset was divided into a near-neutral $(|z / L|<0.5)$ and an unstable part. A linear regression based on the near-neutral measurements of the drag coefficients on the mean wind speed results in

$$
C_{d 10 N}=\left(0.6516+0.0524 u_{10 n}\right) \times 10^{-3},
$$

by assuming that the imbalance is equal to zero under near-neutral conditions (e.g., Large and Pond 1981; Yelland and Taylor 1996; Dupuis et al. 1997). It should be noted that this assumption does not agree with results reported by Thiermann and Graß1 (1992), Frenzen and Vogel (1992), and Edson and Fairall (1998), who found that production generally exceeds dissipation in nearneutral conditions. However, since a number of studies have also found that dissipation exceeds production in near-neutral conditions (e.g., Högström 1990; Smedman et al. 1999), we believe that this is a reasonable assumption with this dataset. The imbalance term can then be derived from the two different estimates of the turbulent fluxes of momentum: the bulk fluxes according to Eq. (12) and the inertial dissipation fluxes. Based on the DD algorithm, taking free convection into account, the imbalance term is calculated by a linear regression to

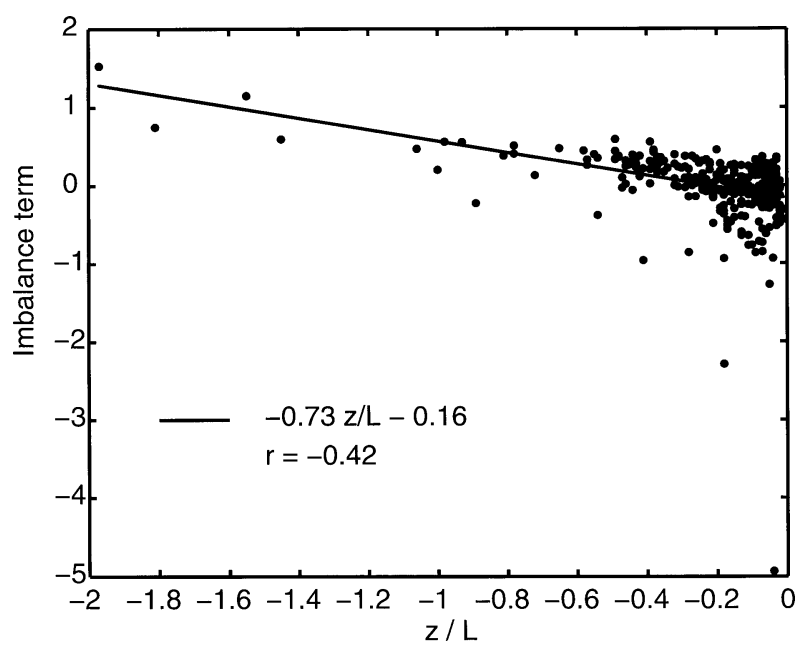

FIG. 5. Scatter diagram of the imbalance term $\Phi_{\text {imb }}$ derived from the two different estimates of $u_{*}$ : the inertial dissipation technique neglecting $\Phi_{\mathrm{imb}}$ and the bulk formulae. For these calculations the DD algorithm is used. The solid line gives the results of a linear regression.

$$
\Phi_{\text {imb }}=-0.73 \frac{z}{L}-0.16
$$

(Fig. 5) using the whole dataset. The correlation coefficient of -0.42 is only low, but according to a Student's t-test significant at the $99 \%$ level. That low correlation might be caused by the fact that most of the time $z / L$ was close to zero due to high observed wind speeds.

This imbalance term agrees well with earlier results of Dupuis et al. (1997), who obtained

$$
\Phi_{\mathrm{imb}}=-0.69 \frac{z}{L}-0.17
$$

taking varying bulk transfer coefficients of heat and free convection into account. This means that the imbalance term increases with increasing deviations from neutral stability, which is in contrast to a study of Edson and Fairall (1998). They estimated the imbalance term from the assumption that for conditions of free convection the imbalance term vanishes. Such different imbalance terms have a strong influence on the resulting drag coefficients. The imbalance term according to Edson and Fairall (1998) gives higher drag coefficients than the imbalance term presented in this study. The differences in the mean are of the order of approximately $10 \%$ for conditions as they were observed during this cruise.

\section{b. Drag coefficient}

Drag coefficients were determined via the inertial dissipation method from spectra of the longitudinal and vertical wind components. Spectral energy densities were calculated from time series of 17-min length.

Figure 6 shows the results using the DB algorithm, where the parameterization scheme of Liu and Blanc 


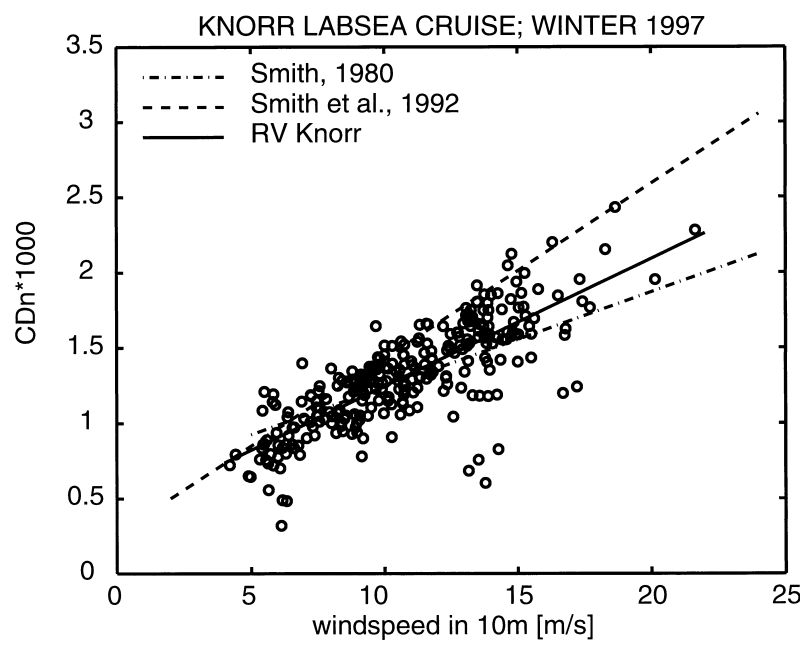

FIG. 6. Estimated drag coefficients reduced to neutral stability and 10 -m height using the DB algorithm. Bulk transfer coefficients used to estimate Monin-Obukhov length are from Smith (1980) and Large and Pond (1982). The solid line is the result of a linear regression of estimated drag coefficients on the mean wind speed at 10-m height. For comparison, drag coefficients of Smith (1980) and Smith et al. (1992) are given.

(1984) was used to derive Monin-Obukhov length. It is based on the model of Liu et al. (1979). It takes into consideration the interfacial sublayers on both sides of the air-sea interface where molecular constraints are important. The flux-profile relations are matched to the logarithmic profiles. Drag coefficients to estimate the roughness lengths $z_{0}$ were adopted from Smith (1980); heat fluxes were calculated via roughness Reynolds numbers. The imbalance term was assumed to be neglegible for estimating the drag coefficient according to the DB algorithm. A linear regression of the drag coefficients $C_{D}$ on the mean wind speed gives

$$
C_{D 10 N}=\left(0.4+0.085 U_{10 N}\right) \times 10^{-3},
$$

reduced for neutral stability and 10-m height. The correlation coefficient is 0.82 . The standard deviation in the estimates of the regression coefficient is $0.017 \times$ $10^{-3}$, the intercept is $0.03 \times 10^{-3}$, and the unexplained variance is $0.22 \times 10^{-3}$ in terms of standard deviation.

The regression of the drag coefficients on the mean wind speed fits well with the results given by Smith (1980), although the estimated regression coefficient is higher. Figure 7 shows the same data using the DD algorithm. Introducing an imbalance term according to Eq. (13) and calculating Monin-Obukhov length iteratively and by making use of fluxes estimated from the sonic anemometer measurements, a linear regression of derived drag coefficients on the mean wind speed gives

$$
C_{D 10 N}=\left(0.54+0.070 U_{10 N}\right) \times 10^{-3}
$$

with a correlation coefficient of about 0.72 (Fig. 7). Standard deviation in the estimate of the regression coefficient is $0.018 \times 10^{-3}$, the error of the intercept 0.03 $\times 10^{-3}$, and the unexplained variance is $0.21 \times 10^{-3}$

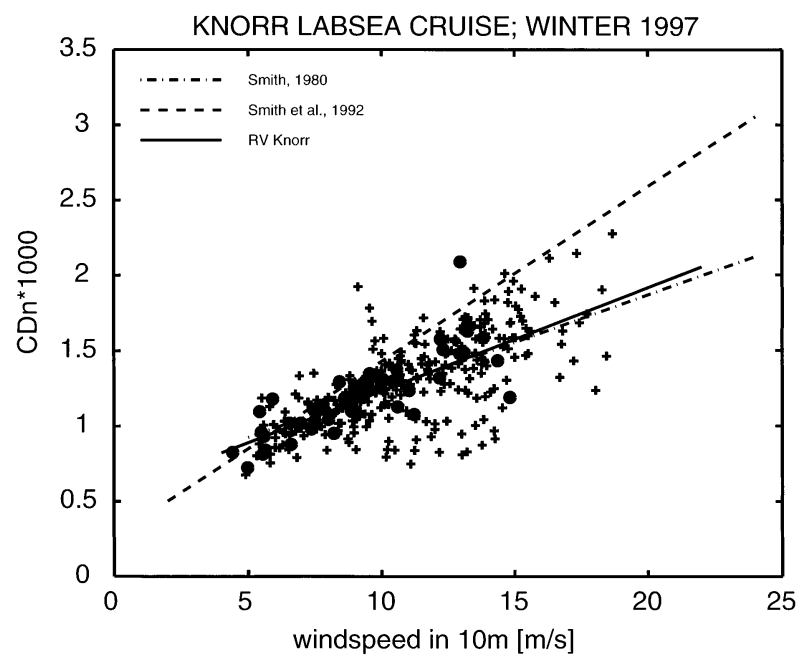

FIG. 7. Estimated drag coefficients reduced to neutral stability and 10 -m height using the DD algorithm. Circles indicate measurements where swell was observed. The solid line is the result of a linear regression of estimated drag coefficients on the mean wind speed at 10-m height. For comparison, drag coefficients of Smith (1980) and Smith et al. (1992) are given.

in terms of standard deviation. Results of the DD algorithm are close to results of the DB algorithm. The introduction of the imbalance term influences mostly the drag coefficients at low wind speeds, where the largest deviations from neutral stability occur. This affects mainly the wind speed dependency of the drag coefficients, where Eqs. (15) and (16) represent the extreme values of the regression coefficients from all possible combinations: DB or DD method with or without neglecting the imbalance term. The coefficients given by Smith (1980) fit our result very well.

As expected, the drag coefficients of the present study are significantly lower than those estimated from the Humidity Exchange over the Sea (HEXOS) Main Experiment (HEXMAX; Smith et al. 1992), where due to limited water depths shallow water waves were observed. Such shallow water waves lead to an increased roughness of the sea surface and therefore to enhanced drag coefficients compared to deep water conditions. The presence of swell may also lead to an increase in the drag coefficient, as recent studies from Janssen (1999) have shown. Swell was observed during the cruise in two manners: visual and with the aid of measurements of the ship's vertical displacement (Fig. 4), where an additional peak at low frequencies was taken as an indicator of the presense of swell. Although the small number of available measurements for situations with swell does not allow comprehensive investigations of the influence of the swell, Fig. 7 indicates no significant change in the drag coefficient for cases with swell compared with measurements in the absense of swell. This is supported by a study of Rutgersson et al. (2000), who showed that swell should have a significant influence on the air-sea fluxes only under stable con- 


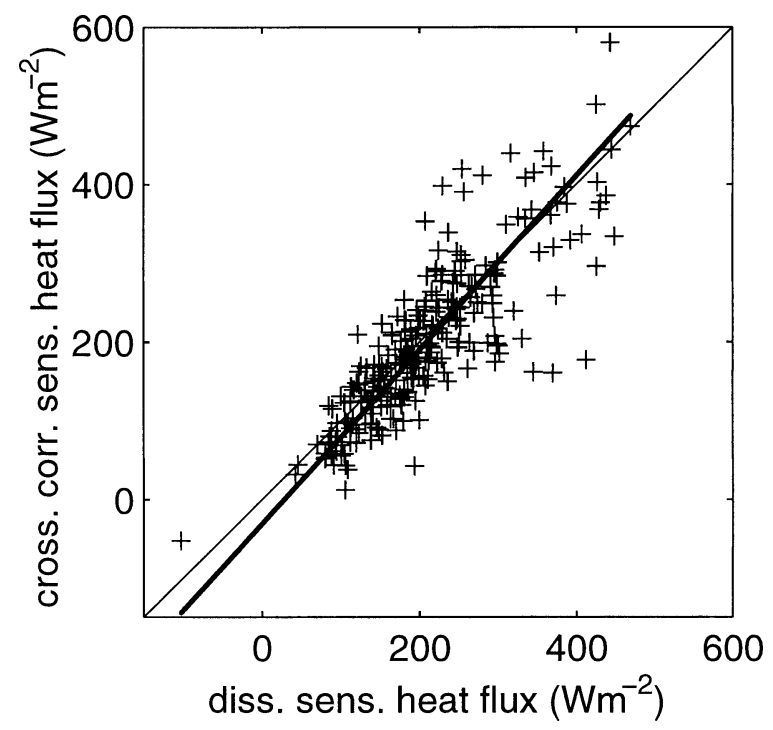

FIG. 8. Sensible heat fluxes estimated using the cross-correlation method vs those estimated using the inertial dissipation method. The solid line gives the result of a linear regression; the dotted line indicates the 1:1 line.

ditions. Such conditions did not occur during the whole cruise.

\section{c. Sensible heat flux}

Sensible heat fluxes were computed using both the cross-correlation and the inertial dissipation methods. Figure 8 compares the results of the two methods. It is obvious that sensible heat fluxes are generally high due to the prevalent weather conditions over the Labrador Sea in wintertime, that is, a large number of days with large air-sea temperature differences and high wind speeds. That is reflected in sensible heat fluxes reaching about $500 \mathrm{~W} \mathrm{~m}^{-2}$ and more.

The average estimated sensible heat flux is $200 \mathrm{~W}$ $\mathrm{m}^{-2}$ for the cross-correlation method and $209 \mathrm{~W} \mathrm{~m}^{-2}$ for the inertial dissipation method. Compared to those values the bias of $9 \mathrm{~W} \mathrm{~m}^{-2}$ between the results of both different methods is low. Standard deviation between simultaneous cross-correlation and dissipation estimates is $55 \mathrm{~W} \mathrm{~m}^{-2}$, which is about $26 \%$ of the average sensible heat flux. We suggest that the differences in the comparison of the methods might be due to uncertainties in the cross-correlation fluxes. That is primarily reducable to the problem of excluding exactly the motions resulting from wind waves and swell due to the limitations of the measurement system.

A neutral linear regression, minimizing the variances of both variables, shows only small deviations from the 1:1 line (Fig. 8, Table 1). Differences depend only slightly on the magnitude of the sensible heat flux itself; the correlation coefficient is about 0.84 . The unexplained variance is $60 \mathrm{~W} \mathrm{~m}^{-2}$ in terms of standard de-

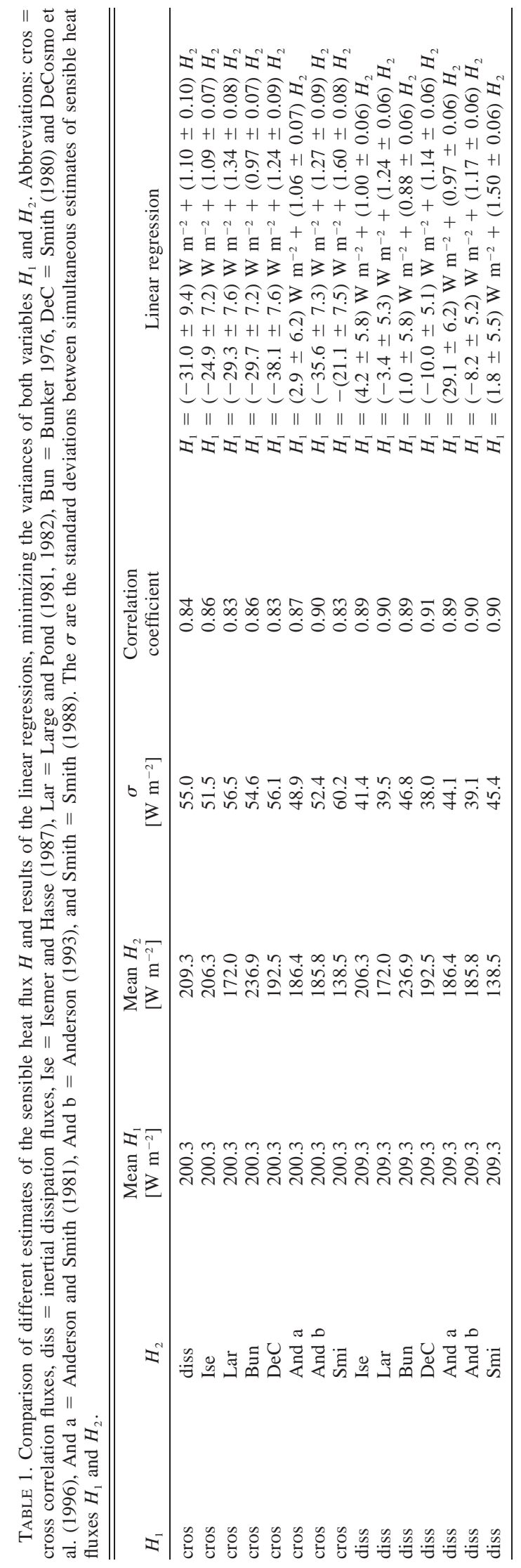



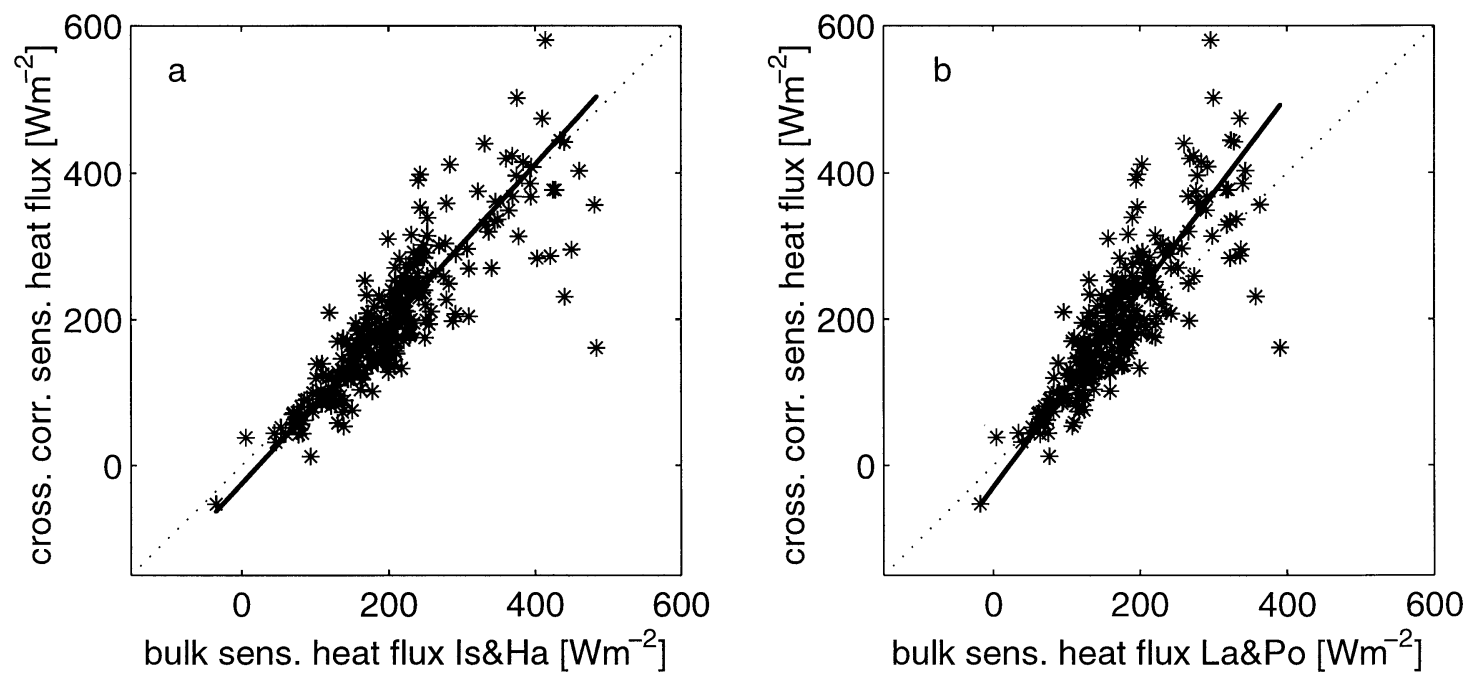

FIG. 9. Sensible heat fluxes estimated using the cross-correlation method compared to sensible heat fluxes calculated by applying a bulk parameterization on the mean values of air temperature, wind speed, and SST. The solid line shows the results of a linear regression; the dotted line indicates the 1:1 line. Bulk transfer coefficients (a) from Isemer and Hasse (1987) and (b) from Large and Pond (1981, 1982).

viation, the error of the intercept $9.4 \mathrm{~W} \mathrm{~m}^{-2}$ and the standard deviation of the regression coefficient 0.1 .

Figures $9 \mathrm{a}$ and $9 \mathrm{~b}$ show a comparison of cross-correlation sensible heat fluxes estimated from the sonic anemometer measurements with fluxes, calculated via a bulk parameterization from 10-min averages of the wind speed, air temperature, and SST as given by the ship's IMET. Bulk parameterizations need input data from specified heights; therefore, mean wind speeds and air temperatures were reduced with respect to height using the parameterization scheme of Liu and Blanc (1984) based on the Businger/Dyer relationships (Businger et al. 1971; Dyer 1974). Bulk transfer coefficients were adopted from Isemer and Hasse (1987) (Fig. 9a). As indicated by a linear fit the differences are small; the correlation coefficient is 0.86 (Table 1). The standard deviation between simultaneous estimates is $51 \mathrm{~W} \mathrm{~m}^{-2}$. In contrast to that, bulk turbulent fluxes according to Large and Pond (1982) are considerably too low (Fig. $9 \mathrm{~b})$. However, the standard deviation of $56 \mathrm{~W} \mathrm{~m}^{-2}$ and the correlation coefficient of 0.83 are of the same order (Table 1). Slightly better results were found in the comparison of dissipation sensible heat fluxes with parameterized fluxes based on the mean quantities (Figs. 10a,b). Standard deviations decrease to $41 \mathrm{~W} \mathrm{~m}^{-2}$ for the bulk parameterization according to Isemer and Hasse (1987) and $40 \mathrm{~W} \mathrm{~m}^{-2}$ for the bulk parameterization using transfer coefficients as given by Large and Pond. Correlation coefficients are high, 0.89 and 0.90 , respectively (Table 1). Again, a linear fit minimizing the variances of both variables shows that a bulk parameterization according to Large and Pond (1982) underestimates sensible heat fluxes compared to our measurements, while a parameterization according to Isemer and Hasse fits well our analyzed sensible heat fluxes.
The measured sensible heat fluxes have also been compared with parameterized fluxes using bulk transfer coefficients from Smith (1988), Bunker (1976), DeCosmo et al. (1996) using drag coefficients according to Smith (1980), Anderson and Smith (1981), and Anderson (1993). Summarized results are given in Table 1. Compared with dissipation sensible heat fluxes, the Bunker parameterization overestimates fluxes by $13 \%$. Parameterizations according to Anderson and Smith (1981), DeCosmo et al. (1996), and Anderson (1993) underestimate the measured fluxes by approximately 10\%; those of Large and Pond (1982) and Smith (1988) underestimate sensible heat fluxes by more than $18 \%$ and $34 \%$ compared to estimates based on the inertial dissipation method.

The better agreement between dissipation sensible heat fluxes and parameterized heat fluxes than between cross-correlation sensible heat fluxes and parameterized heat fluxes in terms of correlation coefficient supports our suggestion that cross-correlation heat fluxes are less accurate than dissipation sensible heat fluxes. Sensible heat fluxes are also available from numerical weather prediction. In general these fluxes are considerably higher than fluxes estimated from our measurements. Close to the ice edge they reach values of about $800 \mathrm{~W} \mathrm{~m}^{-2}$ (Renfrew et al. 2002). This might be caused partly by the algorithms used in numerical models to estimate airsea interaction.

\section{Summary}

Estimated drag coefficients using the inertial dissipation method agree well with results of earlier studies as given, for example, by Smith (1980). For conditions found over the Labrador Sea in wintertime the dissi- 

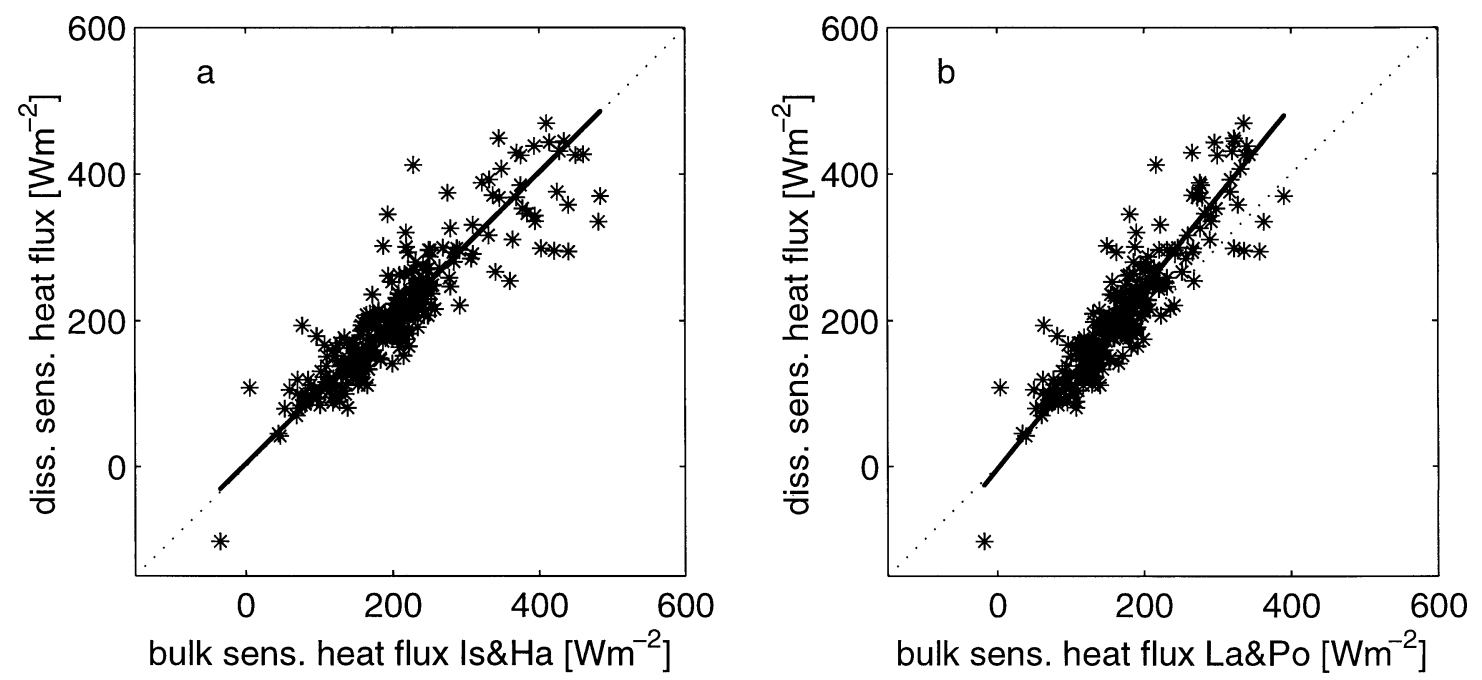

FIG. 10. Sensible heat fluxes estimated using the inertial dissipation method compared to sensible heat fluxes calculated by applying a bulk parameterization on the mean values of air temperature, wind speed, and SST. The solid lines show the results of a linear regression, and the dotted line indicates the 1:1 line. Bulk transfer coefficients (a) from Isemer and Hasse (1987) and (b) from Large and Pond (1981, 1982).

pation-bulk method neglecting the imbalance term came out with results that were close to those using the dissipation-dissipation method taking the imbalance term into account. The imbalance term derived from the sonic anemometer measurements is in a good agreement with earlier findings of Dupuis et al. (1997) under quite different conditions, but the correlation coefficient of the regression is only low. The estimated imbalance term differs considerably from findings of Edson and Fairall (1998). Thus, efforts should be undertaken in the future to improve our knowledge about the imbalance term.

Sensible heat fluxes were estimated using two different methods, the cross-correlation technique and the inertial dissipation method. The results from both methods agree well, indicating that the inertial dissipation method is very useful for analyzing measurements on moving platforms. It was found that the often used bulk transfer coefficients for sensible heat of Large and Pond (1982) or of Smith (1988) lead to a considerable underestimation of sensible heat fluxes under the conditions experienced over the Labrador Sea in winter, that is, large air-sea temperature differences and high wind speeds. Parameterizations according to Isemer and Hasse (1987), Anderson and Smith (1981), DeCosmo et al. (1996), and Anderson (1993) give reasonable results for an area like the Labrador Sea during wintertime.

The datasets above are a useful tool to validate the model output of numerical models or reanalysis data in areas like the Labrador Sea, where direct measurements of air-sea interaction are sparse.

That has been done in a study of Renfrew et al. (2002), which gives detailed comparisons of standard meteorological observations and estimated fluxes with model outputs of the National Centers for Environmental Prediction-National Center for Atmospheric Re- search (NCEP-NCAR) and European Centre for Medium-Range Weather Forecasts (ECMWF) reanalysis projects.

Acknowledgments. The Labrador Sea Deep Convection Experiment is supported by the Office of Naval Research. Our study is supported by the Deutsche Forschungsgemeinschaft as a part of the Sonderforschungsbereich 460 TP B1. We would like to thank Ian Renfrew from the Antarctic Survey for his comments and suggestions. We would like to thank also the crew and the scientific party onboard the R/V Knorr, who supported our work during this Labrador Sea winter cruise.

\section{REFERENCES}

Anderson, R. J., 1993: A study of wind stress and heat flux over the open ocean by the inertial-dissipation method. J. Phys. Oceanogr., 23, 2153-2161.

__ and S. D. Smith, 1981: Evaporation coefficient for the sea surface from eddy flux measurements. J. Geophys. Res., 86 (C1), $449-456$.

Bunker, A. F., 1976: Computations of surface energy flux and annual air-sea interaction cycles of the North Atlantic Ocean. Mon. Wea. Rev., 104, 1122-1140.

Businger, J. A., J. C. Wyngaard, and Y. Izumi, 1971: Flux profile relationships in the atmospheric surface layer. J. Atmos. Sci., 28, 181-189.

DeCosmo, J., K. B. Katsaros, S. D. Smith, R. J. Anderson, W. A. Oost, K. Bumke, and H. Chadwick, 1996: Air-sea exchange of water vapor and sensible heat: The Humidity Exchange over Sea (HEXOS) results. J. Geophys. Res., 101 (C5), 12 001-12 016.

Dupuis, H., P. K. Taylor, A. Weill, and K. Katsaros, 1997: Inertial dissipation method applied to derive turbulent fluxes over the ocean during the surface of the ocean. J. Geophys. Res., 102 (C9), 21 115-21 129.

Dyer, A. J., 1974: A review of flux profile relationships. Bound.Layer Meteor., 7, 363-372.

Edson, J. B., and C. W. Fairall, 1998: Similarity relationships in the 
marine atmospheric surface layer for terms in the TKE and scalar variance budgets. J. Atmos. Sci., 55, 2311-2328.

Frenzen, P., and C. A. Vogel, 1992: The turbulent kinetic energy budget in the atmospheric surface layer: A review and an experimental reexamination in the field. Bound.-Layer Meteor., 60, $49-76$.

Gravech, A. A., C. W. Fairall, and S. E. Larsen, 1998: On the determination of the neutral drag coefficient in the convective boundary layer. Bound.-Layer Meteor., 86, 257-278.

Högström, U., 1990: Analysis of turbulence structure in the surface layer with a modified similarity formulation for near neutral conditions. J. Atmos. Sci., 47, 1949-1972.

_ - 1996: Review of some basic characteristics of the atmospheric surface layer. Bound.-Layer Meteor., 78, 215-246.

Isemer, H. J., and L. Hasse, 1987: The Bunker Climate Atlas of the North Atlantic Ocean. Vol. 2: Air-Sea Interactions. Springer, $256 \mathrm{pp}$.

Janssen, P. A. E. M., 1999: On the effect of ocean waves on the kinetic energy balance and consequences for the inertial dissipation technique. J. Phys. Oceanogr., 29, 530-534.

Kaimal, J. C., and J. E. Gaynor, 1991: Another look at sonic thermometry. Bound.-Layer Meteor., 56, 401-410.

Lab Sea Group, 1998: The Labrador Sea Deep Convection Experiment. Bull. Amer. Meteor. Soc., 79, 2033-2058.

Large, W. G., and S. Pond, 1981: Open ocean flux measurements in moderate to strong winds. J. Phys. Oceanogr., 11, 324-336.

, and - 1982: Sensible and latent heat flux measurements over the ocean. J. Phys. Oceanogr., 12, 464-482.

Liu, W. T., and T. V. Blanc, 1984: The Liu, Katsaros, and Businger (1979) bulk atmospheric flux computational iteration program in FORTRAN and BASIC. NRL Memo. Rep. 5291, Naval Research Laboratory, Washington D.C., 16 pp.

$\ldots$, K. B. Katsaros, and J. A. Businger, 1979: Bulk parameteri- zations of air-sea exchanges of heat and water vapor including the molecular constraints at the interface. J. Atmos. Sci., 36, $1722-1735$.

Moat, B., and M. Yelland, 1998: Airflow distortion at instrument sites on the R/V Knorr. Southampton Oceanography Centre, 29 pp.

Renfrew, I. A., G. W. K. Moore, P. S. Guest, and K. Bumke, 2002 A comparison of surface layer and surface turbulent flux observations over the Labrador Sea with ECMWF analyses and NCEP reanalyses. J. Phys. Oceanogr., 32, 383-400.

Rutgersson, A., A.-S. Smedman, and U. Högström, 2000: The use of conventional stability parameters during swell. Water and Heat Exchange Processes Over the Baltic Sea. A. Rutgersson, Ed., Vol. 530, Comprehensive Summaries of Uppsala Dissertations from the Faculty of Science and Technology, University of Uppsala, $32 \mathrm{pp}$.

Smedman, A., U. Högström, H. Bergström, and A. Rutgersson, 1999: A case study of air-sea interaction during swell conditions. $J$. Geophys. Res., 104 (C11), 25 833-25 851.

Smith, S. D., 1980: Wind stress and heat flux over the ocean in gale force winds. J. Phys. Oceanogr., 10, 709-726.

_ 1988: Coefficients for sea surface wind stress, heat flux, and wind profiles as a function of wind speed and temperature. $J$. Geophys. Res., 93 (C12), 15 467-15 472.

_ ficients. Bound.-Layer Meteor., 60, 109-142.

Thiermann, V., and H. Graß1, 1992: The measurement of turbulent surface layer fluxes by use of bichromatic scintillation. Bound.Layer Meteor., 58, 367-389.

Wucknitz, J., 1978: The influence of anisotropy on stress estimation by the indirect dissipation method. Bound.-Layer Meteor., 17, 119-131.

Yelland, M. J., and P. K. Taylor, 1996: Wind stress measurements from the open ocean. J. Phys. Oceanogr., 26, 541-558. 